\title{
Targeting Amino Acid Metabolism for Molecular Imaging of Inflammation Early After Myocardial Infarction
}

\author{
James T. Thackeray ${ }^{1}$, Jens P. Bankstahl ${ }^{1}$, Yong Wang ${ }^{2}$, Kai C. Wollert ${ }^{2}$ and Frank M. Bengel ${ }^{1}$ \\ 1. Department of Nuclear Medicine, Hannover Medical School, Hannover, Germany; \\ 2. Division of Molecular and Translational Cardiology, Department of Cardiology and Angiology, Hannover Medical School, Hannover, Germany. \\ $\square$ Corresponding author: James T Thackeray, PhD. Department of Nuclear Medicine, Hannover Medical School, Carl-Neuberg-Str. 1, D-30625 Hannover, \\ Germany; Tel: +49-511-532-3358, Fax: +49-511-532-3761, E-Mail: Thackeray.James@mh-hannover.de.
}

(1) Ivyspring International Publisher. Reproduction is permitted for personal, noncommercial use, provided that the article is in whole, unmodified, and properly cited. See http://ivyspring.com/terms for terms and conditions.

Received: 2016.04.22; Accepted: 2016.05.23; Published: 2016.07.15

\begin{abstract}
Acute tissue inflammation after myocardial infarction influences healing and remodeling and has been identified as a target for novel therapies. Molecular imaging holds promise for guidance of such therapies. The amino acid ${ }^{11} \mathrm{C}$-methionine is a clinically approved agent which is thought to accumulate in macrophages, but not in healthy myocytes. We assessed the suitability of positron emission tomography (PET) with ${ }^{11} \mathrm{C}$-methionine for imaging post-MI inflammation, from cell to mouse to man. Uptake assays demonstrated 7-fold higher ${ }^{11} \mathrm{C}$-methionine uptake by polarized pro-inflammatory $\mathrm{Ml}$ macrophages over anti-inflammatory $\mathrm{M} 2$ subtypes $(\mathrm{p}<0.001)$. C57BI/6 mice $(n=27)$ underwent coronary artery ligation or no surgery. Serial ${ }^{11} C$-methionine PET was performed 3, 5 and $7 d$ later. MI mice exhibited a perfusion defect in $32-50 \%$ of the left ventricle (LV). PET detected increased ${ }^{11} \mathrm{C}$-methionine accumulation in the infarct territory at $3 \mathrm{~d}$ $(5.9 \pm 0.9 \% \mathrm{ID} / \mathrm{g}$ vs $4.7 \pm 0.9$ in remote myocardium, and $2.6 \pm 0.5$ in healthy mice; $p<0.05$ and $<0.01$ respectively), which declined by $\mathrm{d} 7$ post-MI $(4.3 \pm 0.6$ in infarct, $3.4 \pm 0.8$ in remote; $p=0.03$ vs $3 \mathrm{~d}$, $\mathrm{p}=0.08$ vs healthy). Increased ${ }^{11} \mathrm{C}$-methionine uptake was associated with macrophage infiltration of damaged myocardium. Treatment with anti-integrin antibodies (anti-CD1 la, -CD1 lb, -CD49d; $100 \mu \mathrm{g}$ ) lowered macrophage content by $56 \%$ and ${ }^{11} \mathrm{C}$-methionine uptake by $46 \%$ at $3 \mathrm{~d}$ post-MI. A patient study at $3 \mathrm{~d}$ after ST-elevation $\mathrm{MI}$ and early reperfusion confirmed elevated ${ }^{11} \mathrm{C}$-methionine uptake in the hypoperfused myocardial region. Targeting of elevated amino acid metabolism in pro-inflammatory MI macrophages enables PET imaging-derived demarcation of tissue inflammation after MI. ${ }^{11} \mathrm{C}$-methionine-based molecular imaging may assist in the translation of novel image-guided, inflammation-targeted regenerative therapies.
\end{abstract}

Key words: inflammation, myocardial infarction, ${ }^{11} \mathrm{C}$-methionine, macrophages, positron emission tomography (PET).

\section{Introduction}

In acute myocardial infarction (MI), activated inflammatory leukocytes invade the area at risk within hours after primary insult, accumulating over several days. While needed for appropriate repair, suppressed or excessive inflammation also contributes to the risk of cardiac rupture, infarct instability or subsequent left ventricular remodeling [1]. Targeted therapies to modulate the inflammatory process following MI are theorized to support the healing process and improve functional outcome, but require appropriate timing [2, 3]. Molecular imaging may provide a platform for longitudinal, noninvasive, and quantitative monitoring of inflammation progression and regression [4]. Such an approach may assist in candidate selection and in assessment of response to novel therapies.

Using ${ }^{18} \mathrm{~F}$-fluoro-deoxyglucose (FDG), positron emission tomography (PET) of myocardial inflammation has been employed in the preclinical and clinical setting [5-7]. However, FDG uptake by 
viable cardiomyocytes may be a confounding factor which obscures the inflammatory signal and necessitates the use of protocols to suppress endogenous myocyte FDG transport [8, 9]. This limitation of FDG-based inflammation imaging stimulates the search for alternative radiotracers for the evaluation of myocardial inflammation.

${ }^{11}$ C-Methionine is a well characterized positron-emitting marker of amino acid uptake and de novo protein synthesis, used routinely in clinical oncology for the characterization of brain tumors and other malignancies [10, 11]. A preliminary study identified myocardial uptake of ${ }^{11} \mathrm{C}$-methionine in acute myocardial infarction patients at up to 2 weeks after coronary reperfusion [12]. Moreover, recent ex vivo evidence suggested that methionine may serve as a potential marker of post-infarct inflammation [13].

We hypothesized that post-ischemia inflammation would be associated with accumulation in activated macrophages, and could be serially visualized with ${ }^{11} \mathrm{C}$-methionine and small animal PET. In vitro studies established preferential tracer uptake into activated macrophages. In vivo imaging studies in healthy mice and following permanent ligation of a coronary artery demonstrate a spatial and temporal pattern of ${ }^{11} \mathrm{C}$-methionine consistent with leukocyte infiltration of inflamed tissue, sensitive to suppression of inflammation by anti-integrin therapy. A clinical case supports the translational potential of the approach.

\section{Methods}

Materials and Radiochemistry. ${ }^{11} \mathrm{C}$-Methionine was synthesized as described by $S$-methylation of S-benzyl-homocysteine [14], obtaining high radiochemical purity $(>98 \%)$ and specific activity $(>10 \mathrm{GBq} / \mu \mathrm{mol})$. Cell culture medium and cytokines were acquired from Sigma Aldrich. Antibodies and reagents for magnetic immunoseparation of leukocytes were purchased from Miltenyi. In vivo antibodies were obtained from BioXcell.

Cell Culture. Macrophages were cultured as described elsewhere [15]. Human monocyte THP-1 cells were cultured and expanded in enriched RPMI 1640 medium $(2 \mathrm{mM}$ glutamine, $0.05 \mathrm{mM}$ $\beta$-mercaptoethanol, $10 \%$ fetal calf serum (FCS)). After 6 days, cells were collected and seeded onto fibronectin-coated 6-well plates $\left(2.5 \times 10^{5}, 5 \times 10^{5}\right.$, or $1 \times 10^{6}$ per well) under fresh RPMI 1640, supplemented with 20\% FCS and macrophage colony-stimulating factor (M-CSF, $100 \mathrm{ng} / \mathrm{ml}$ ) to promote differentiation to macrophages over 4 days.

To assess the subtype of macrophages responsible for methionine uptake, cultured macrophages $\left(1 \times 10^{6}\right)$ were stimulated with cytokines to generate pro- and anti-inflammatory subsets as described elsewhere [15]. Briefly, after $4 \mathrm{~d}$ of culture with M-CSF-enriched medium, the supernatant was replaced with RPMI 1640 (10\% FCS) supplemented with either lipopolysaccharide $(100 \mathrm{ng} / \mathrm{mL})$ and IFN- $\gamma$ (20 ng/mL) to polarize M1 macrophages, IL-4 (20 $\mathrm{ng} / \mathrm{mL}$ ) to polarize M2 macrophages, or IL-10 (100 $\mathrm{ng} / \mathrm{mL}$ ) to polarize M2a macrophages. After $48 \mathrm{~h}$ of stimulation, medium was removed and replaced with modified culture medium (methionine-, glutamine-, cysteine-free RPMI164) 1h prior to the uptake assay for acclimatization.

Magnetic Bead Immunoseparation. To further characterize the cellular uptake of methionine, leukocyte subtypes were purified from human blood samples by magnetic-associated antibody cell sorting [16]. Briefly, white blood cells were separated from whole blood by centrifugation with Ficoll reagent. Leukocytes were suspended in PBS containing 4\% FCS and 2mM EDTA (MACS buffer) and incubated with biotin-conjugated antibody (1/11 dilution per $10^{7}$ cells $\left./ 100 \mu \mathrm{L}, 15 \mathrm{~min}, 4^{\circ} \mathrm{C}\right)$. Cell fractions of neutrophils (Anti-CD177, clone REA258), monocytes and macrophages (Anti-CD11b, clone M1/70.15.11.5), and T-cells / natural killer (NK) cells (Anti-CD2, clone LT2) were collected. An isolation kit was used to obtain a purified B cell fraction by negative selection. Specifically, a cocktail of biotin-conjugated antibodies against CD2, CD14, CD16, CD36, CD43, CD235a/Glycophorin A was added to washed cells $\left(1 / 11\right.$ dilution per $10^{7}$ cells $\left./ 100 \mu \mathrm{L}, 15 \mathrm{~min}, 4^{\circ} \mathrm{C}\right)$. Labeled cells were washed twice in MACS washing buffer, then incubated with anti-biotin MicroBeads according to the manufacturer's instructions $\left(20 \mu \mathrm{L} / 10^{7}\right.$ cells, $\left.15 \mathrm{~min}, 4^{\circ} \mathrm{C}\right)$. After an additional wash step, cells were resuspended and applied to a MACS column containing ferromagnetic spheres and placed in a MACS cell separator. After washing, retained cells were eluted from the column outside of the magnetic field to provide the neutrophil, monocyte/macrophage, and T-/NK cell fractions. For $B$ cells, the column efflux was collected. Cell fractions were counted and maintained in MACS buffer overnight prior to uptake assay. The following morning, cells were centrifuged, resuspended and counted, then divided into aliquots of $5 \times 10^{5}$ cells in microcentrifuge tubes.

Methionine Uptake Assays. Uptake assays were conducted with ${ }^{11} \mathrm{C}$ - or ${ }^{14} \mathrm{C}$-methionine following established protocols [15, 17], with minor modifications. Culture medium was changed prior to experiments to modified (methionine-, glutamine-, cysteine-free) RPMI 1640. Labeled methionine was added to the cell culture medium and incubated at 
$37^{\circ} \mathrm{C}$ for $30-60 \mathrm{~min}$. To determine non-specific uptake, selected wells were supplemented with excess unlabeled methionine. After incubation, residual medium was removed, cells were washed twice with ice cold phosphate buffered saline (PBS), and finally lysed with $1 \mathrm{~mol} / \mathrm{L}$ sodium hydroxide, $0.1 \%$ sodium dodecylsulfate. Non-adherent leukocytes were centrifuged ( $300 \times \mathrm{g}, 5 \mathrm{~min})$ between steps to facilitate removal of supernatant. Collected lysate was counted for radioactivity in a gamma counter (Gamma Wizard, Perkin Elmer) or beta-scintillation counter (Rack Beta, Perkin-Elmer). Decay-corrected counts were normalized to the injected dose and analysed relative to the number of plated cells.

Animals. All animal experiments were conducted in accordance with the European Union Guidelines for the Use and Care of Laboratory Animals, and with the approval of the local authorities. Male C57Bl/6N mice $(\mathrm{n}=27$, Charles River, $24.6 \pm 1.5$ g) were housed on a $14 \mathrm{~h} / 10 \mathrm{~h}$ light/dark cycle with standard laboratory diet and water ad libitum. A subgroup $(\mathrm{n}=22)$ underwent coronary artery ligation as described previously [18]. Following pretreatment with butorphanol analgesic (2 $\mathrm{mg} / \mathrm{kg} \mathrm{sc}$ ), mice were anesthetized ( $3 \%$ isoflurane, induction), intubated and ventilated (1.5-2\% isoflurane); left thoracotomy exposed the heart, the left coronary artery was identified and permanently ligated with a silk suture. Mice recovered over 3 days prior to PET imaging. ${ }^{11} \mathrm{C}-$ Methionine PET imaging was conducted on day 3, 5 and 7 post-MI.

Anti-Integrin Treatment. To determine the sensitivity of ${ }^{11} \mathrm{C}$-methionine uptake towards attenuation of inflammation, a group of post-MI mice $(n=12)$ was treated with an anti-integrin antibody cocktail consisting of anti-CD11a (lymphocyte function-associated antigen-1, LFA-1, Clone M17/4), anti-CD11b (macrophage-1 antigen, Mac-1, Clone M1/70), and anti CD49d (very late antigen-4, VLA-4, Clone PS/2). Anti-integrin treatment $(100 \mu \mathrm{g})$ was injected ip $2 \mathrm{~h}$ prior to surgery with a maintenance dose on day 4 post-MI [2]. The efficacy of anti-integrin therapy was verified by magnetic immunoseparation at $3 \mathrm{~d}$ post-MI. Briefly, the heart was excised and washed in PBS to remove residual blood. The atria and right ventricle were removed, and the left ventricle was weighed, minced, and digested in $1 \mathrm{~mL}$ of digestion buffer (collagenase $1 \mathrm{mg} / \mathrm{mL}$, Roche; DNAse I $100 \mathrm{U} / \mathrm{mL}$, Sigma; dispase $2.4 \mathrm{mg} / \mathrm{mL}$, Invitrogen) for $30 \mathrm{~min}$ at $37^{\circ} \mathrm{C}$ with periodic dissociation (x2, MACS Dissociator, Miltenyi). After centrifugation $\left(300 \mathrm{~g}, 7 \mathrm{~min}, 4^{\circ} \mathrm{C}\right)$, the cell pellet was washed with PBS, then centrifuged again and resuspended in $300 \mu \mathrm{L}$ MACS buffer. Nonspecific binding was blocked with anti-mouse CD16/32 (1/60 dilution, $10 \mathrm{~min}, 4^{\circ} \mathrm{C}$ ). Cells were then sequentially incubated with biotin-conjugated anti-CD11b (1/11 dilution, $15 \mathrm{~min}, 4^{\circ} \mathrm{C}$ ) and anti-biotin Microbeads $\left(20 \mu \mathrm{L}, 10 \mathrm{~min}, 4^{\circ} \mathrm{C}\right)$ for magnetic separation. Labeled cells were washed with PBS, centrifuged, resuspended under MACS buffer, and applied to a column containing ferromagnetic spheres and within a magnetic cell separator. Column efflux (CD11b-) was collected and retained cells $(\mathrm{CD} 11 \mathrm{~b}+)$ were eluted outside of the magnetic field. CD11b+ cells were manually counted using a neubauer cell counting chamber under a microscope (2-3 counts per sample).

In Vivo PET Imaging. PET images were obtained in all mice using the Inveon DPET small animal camera (Siemens) [7, 19]. ${ }^{11} \mathrm{C}-$ Methionine (17.2 $5.4 \mathrm{MBq}$, range $7.8-28.3 \mathrm{MBq})$ was injected in a maximum $0.2 \mathrm{~mL}$ bolus into a lateral tail vein via catheter, followed by a $0.1 \mathrm{~mL}$ flush of heparinized saline $(\sim 5 \mathrm{U} / \mathrm{kg})$. In order to scan the maximal number of animals for each tracer synthesis, the range of dose was somewhat broad. We observed no difference in the uptake of ${ }^{11} \mathrm{C}$-methionine across this dose range. In all studies, tracer doses $(<10 \mathrm{nmol})$ are administered, and no physiological effects of administered cold mass was expected. Dynamic list mode data were acquired over $30 \mathrm{~min}$ (Suppl Figure S1). A ${ }^{57} \mathrm{Co}$ transmission scan was completed for attenuation correction and a low-dose CT was acquired for coregistration. Listmode PET data were histogrammed to 28 frames of $5 \times 2 \mathrm{~s}, 4 \times 5 \mathrm{~s}, 3 \times 10 \mathrm{~s}$, $8 \times 30$ s, $5 \times 60$ s, $2 \times 300$ s, $1 \times 600$ s, and reconstructed to a $128 \times 128 \times 159$ image matrix $(0.78 \times 0.78 \times 0.80 \mathrm{~mm})$ using a $3 \mathrm{D}$ ordered subset expectation maximization / maximum a posteriori algorithm $(\beta=1$, OSEM iterations $=2$, MAP iterations $=18$ ) with scatter and decay correction applied as per the manufacturer defaults.

Perfusion Imaging. To identify the infarct territory, a perfusion SPECT scan was obtained in post-MI mice using 99mTc-sestamibi. Immediately following the PET scan, $99 \mathrm{~m}$ Tc-sestamibi $(99.2 \pm 8.1$ $\mathrm{MBq}$ ) was administered via the same tail vein catheter. After 30 minute uptake period, SPECT acquisition was performed using the cadmium zinc telluride equipped Explore speCZT camera with a mouse 7-pinhole collimator (Trifoil Imaging). Projection data were acquired in step-and-shoot mode with 50 views for each pinhole (350 total views), $1.06^{\circ}$ increment angle, and 30s acquisition for each step. Energy threshold was $60 \mathrm{keV}$, with a reconstruction

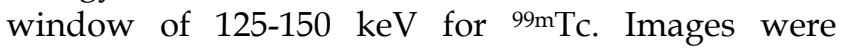
reconstructed using maximum likelihood expectation maximization with 50 iterations to a $128 \times 128 \times 80$ image matrix ( $0.33 \mathrm{~mm}$ pixel size). Scanner energy correction, uniformity correction, and resolution 
recovery filter were applied as per manufacturer defaults. A second low-dose CT was acquired using the Explore speCZT camera to facilitate image fusion between PET/CT and SPECT/CT images.

Image Analysis. Data were analysed using Inveon Research Workplace software (Siemens). Regions of interest for left ventricular myocardium, skeletal muscle (quadriceps femoris), brain, spleen, thymus, liver, and kidneys were defined using PET images and coregistration CT for anatomic landmarks. Image-derived input function was obtained from a region of interest at the left atrial cavity, identified in the initial frames of the dynamic PET image. Whole body image-derived biodistribution was calculated as percent injected dose per gram (\%ID/g) for each organ ROI at 20-30 min after injection. Polar maps for the perfusion and ${ }^{11} \mathrm{C}$-methionine images were generated using Munich Heart software and normalized to maximal activity. A 17-segment model was applied to the resulting polar maps to determine the regional distribution of ${ }^{11}$ C-methionine.

Ex vivo Validation. At both 3 and 7d post-MI, following the imaging session, a subset of mice $(n=3)$ were selected for ex vivo autoradiography as described previously [7]. Briefly, mice were killed by cervical dislocation, the thoracic cavity opened, and heart retrograde-perfused with ice-cold PBS. Perfused hearts were rapidly excised and snap frozen in OCT compound (Tissue Tek). Cryosections $(10 \mu \mathrm{m})$ at 200 $\mu \mathrm{m}$ increments were immediately sliced and thaw-mounted onto Superfrost+ microscope slides, with sequential sections allocated for autoradiography exposure and histology. Slides were exposed to a supersensitive phosphor screen for $2 \mathrm{~h}$ in a light-impermeable cassette, then scanned using a phosphor imager (Cyclon). Resulting images were analysed semi-quantitatively by calculating the ratio of regional densitometry in the anterolateral (infarct) wall to an equivalent sized area in the inferolateral (remote) wall. Measurements from 3-4 sections at each level were combined as apical or basal to the coronary ligature. To further validate the in vivo imaging result, CD11b+ cells isolated from the left ventricle of infarcted mice at $3 \mathrm{~d}$ post-MI by magnetic immunoseparation were used for cell uptake assays with labeled methionine as described above.

Histology. Adjacent sections were processed for histopathology. Hematoxylin/eosin staining defined general myocardial morphology; Masson Trichrome staining identified collagen deposition and fibrosis. Leukocyte infiltration was identified by immunostaining for CD68-positive macrophages or Ly6G-positive granulocytes.
Clinical Study. A patient underwent myocardial perfusion SPECT and ${ }^{11} \mathrm{C}$-methionine PET at $3 \mathrm{~d}$ after first acute ST-elevation myocardial infarction followed by percutaneous coronary intervention for reperfusion of the occluded right coronary artery. Imaging was obtained for clinical purposes according to $\$ 13.2 \mathrm{~b}$ of the German Pharmaceuticals Act (AMG). The patient provided informed written consent prior to imaging.

Statistics. All data are presented as mean \pm standard deviation. Uptake assay measurements and imaging groups were compared by Kruskal Wallis non-parametric statistics. Serial imaging and autoradiography data were compared using Student's paired t-test. Significance was considered at $\mathrm{p}<0.05$.

\section{Results}

\section{Cultured Macrophages Specifically Take Up Radiolabeled Methionine.}

To determine the feasibility of methionine imaging of inflammatory cells, we first measured uptake in vitro by cultured THP-1 derived human macrophages. Uptake by cultured macrophages increased proportionally to the number of seeded cells $\left(1.0 \times 10^{5}, 2.8 \pm 0.1 \% ; \quad 2.5 \times 10^{5}, 3.6 \pm 0.6 \% ; \quad 5.0 \times 10^{5}\right.$, $4.2 \pm 0.6 \% ; \mathrm{r}=0.78, \mathrm{p}<0.01)$. Incubation with excess unlabeled methionine reduced tracer retention to background level, supporting specificity (Figure 1A).

We next evaluated the specific cell populations responsible for methionine uptake by generating polarized THP-1 derived macrophages by cytokine stimulation and isolating purified leukocyte fractions from human blood samples using magnetic immunoseparation. In polarized THP-1-derived macrophages, pro-inflammatory M1 cells exhibited 7.5-fold higher uptake as compared to anti-inflammatory M2 and M2a cells (M1 0.99 $\pm 40 \%$; M2 0.05 \pm 0.03 ; M2a 0.06 $\pm 0.01, \mathrm{p}<0.001$ ) (Figure 1B). Among leukocyte subpopulations purified from peripheral blood by magnetic-associated cell sorting, the highest uptake was observed in CD11b+ monocytes/macrophages $(0.52 \pm 0.07 \%)$ and CD177+ neutrophils $(0.52 \pm 0.17 \%)$. Methionine accumulation was modestly lower in $\mathrm{CD} 2+\mathrm{T}-/ \mathrm{NK}$ cells $(0.43 \pm 0.05 \%, p=0.04)$, and distinctly lower in B cells $(0.08 \pm 0.02, \mathrm{p}<0.001)$ (Figure $1 \mathrm{C}$ ).

\section{"C-Methionine Displays No Uptake by Healthy Murine Myocardium.}

Distribution of ${ }^{11} \mathrm{C}$-methionine was evaluated in healthy mice to provide a baseline and estimation of the background signal for comparison in disease and inflammatory states. High tracer accumulation was observed in leukocyte-rich regions including the 
spleen, thymus and bone marrow, and by the liver as a metabolic organ (Table 1). By contrast, healthy myocardium exhibited low uptake that was poorly distinguished from background (Figure 2A and B). Time activity curves confirmed poor definition of myocardium versus blood pool over 30min (Suppl Figure S2A), suggesting a low background signal for isolation of inflammatory cell uptake.

\section{C-Methionine Accumulates in the Infarct Territory after Coronary Artery Ligation.}

We then proceeded to evaluate inflammation in an acute infarct model, with serial ${ }^{11} \mathrm{C}$-methionine PET imaging at 3,5, and $7 \mathrm{~d}$ after MI. The perfusion defect as defined by ${ }^{99 \mathrm{~m} T c-s e s t a m i b i}$ polar map analysis amounted to $44 \pm 9 \%$ of the left ventricle. In contrast to healthy hearts, post-infarct myocardium exhibited defined uptake of ${ }^{11} \mathrm{C}$-methionine (Figure $2 \mathrm{~A}$ and $\mathrm{B})$, with maximal uptake in the infarcted anterolateral wall $(5.9 \pm 0.9 \% \mathrm{ID} / \mathrm{g})$. An increase in tracer accumulation was also observed in the non-infarcted myocardium $(4.7 \pm 0.9 \% \mathrm{ID} / \mathrm{g})$. This increased activity was gradually diminished at day 5 (infarct $5.4 \pm 0.7 \% \mathrm{ID} / \mathrm{g}$; remote $4.1 \pm 07 \% \mathrm{ID} / \mathrm{g}$ ) and day 7 (infarct $4.3 \pm 0.6 \% \mathrm{ID} / \mathrm{g}$; remote $3.4 \pm 0.8 \% \mathrm{ID} / \mathrm{g}$ ) (Figure 2C). Time activity curves demonstrated elevated area under the curve for myocardium and deviation from the blood pool at 3 and 5 days post-MI. By 7 days post-MI, this separation of the time activity curves is ablated (Suppl Figure S2). Distribution in other organs was comparable to healthy mice (Table $1)$, with modest reduction in bone marrow activity over $7 \mathrm{~d}$. Regional evaluation of tracer distribution by polar map analysis demonstrated mismatched regions

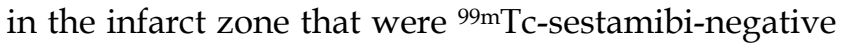
but ${ }^{11} \mathrm{C}$-methionine-positive. The highest uptake of ${ }^{11} \mathrm{C}$-methionine was localized to the boundaries of the infarct territory at $3 \mathrm{~d}$ and was decreased over $7 \mathrm{~d}$ post-MI.

Table 1. Whole body distribution (\%ID/g) of "IC-methionine in healthy and post-infarct mice.

\begin{tabular}{lllll}
\hline & Control & MI+3d & MI+5d & MI+7d \\
\hline Myocardium & $2.6 \pm 0.5$ & $3.9 \pm 0.2^{\dagger \dagger}$ & $3.8 \pm 0.3^{\dagger \dagger}$ & $2.7 \pm 0.4$ \\
Spleen & $25.9 \pm 10.1^{*}$ & $14.5 \pm 1.7^{*}$ & $18.4 \pm 5.9^{*}$ & $18.0 \pm 2.1^{* *}$ \\
Thymus & $4.9 \pm 0.6^{* *}$ & $5.3 \pm 0.4$ & $5.2 \pm 0.4^{*}$ & $4.0 \pm 0.8^{*}$ \\
Bone Marrow & $4.8 \pm 0.5^{* *}$ & $4.3 \pm 0.3$ & $4.2 \pm 0.3^{\dagger}$ & $3.3 \pm 0.7^{\dagger}$ \\
Brain & $2.7 \pm 0.5$ & $2.9 \pm 0.4^{*}$ & $2.6 \pm 0.1^{*}$ & $2.2 \pm 0.4^{* *}$ \\
Quadriceps & $2.3 \pm 0.2$ & $2.3 \pm 0.3^{* *}$ & $2.9 \pm 0.3^{* \dagger}$ & $2.2 \pm 0.6$ \\
Liver & $13.9 \pm 1.2^{* *}$ & $14.3 \pm 1.3^{* *}$ & $15.0 \pm 2.0^{* *}$ & $11.4 \pm 2.4^{*}$ \\
Kidney & $7.1 \pm 0.6^{* *}$ & $7.2 \pm 1.5^{*}$ & $9.9 \pm 1.7^{* \dagger}$ & $6.5 \pm 1.1^{* *}$ \\
Blood & $1.3 \pm 0.3^{* *}$ & $1.7 \pm 0.2^{* *}+$ & $1.9 \pm 0.2^{* *} \dagger$ & $1.3 \pm 0.3^{*}$
\end{tabular}

${ }^{*} \mathrm{p}<0.05$, ** $\mathrm{p}<0.01$ vs myocardium, matched group.

$\dagger \mathrm{p}<0.05$, t† $\mathrm{p}<0.01$ vs control, matched organ.

B
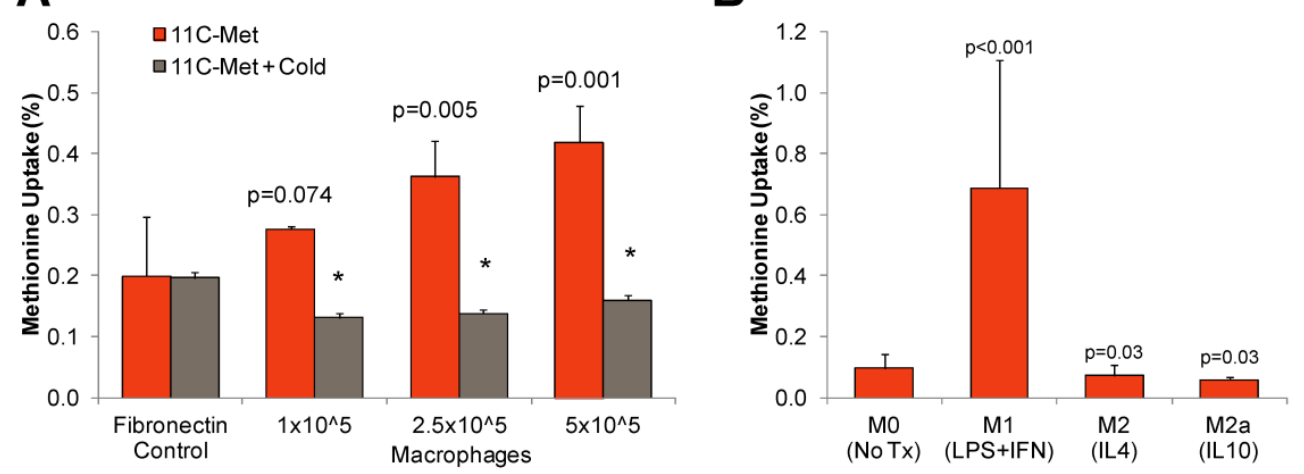

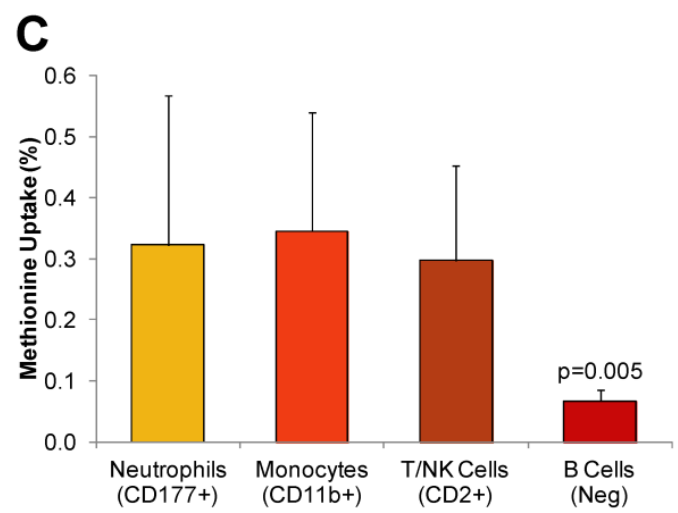

Figure 1. " C-Methionine uptake by isolated cultured leukocytes. A, Uptake assays conducted in THP-1 derived macrophages cultured at increasing plating density in the presence and absence of excess unlabled methionine (cold). B, Uptake assays conducted in polarized pro-inflammatory (M1) and anti-inflammatory (M2, M2a) THP-derived macrophages. C, Uptake of ${ }^{14} \mathrm{C}$-methionine by leukocyte subtypes isolated from peripheral human blood by magnetic immunoseparation. Values are mean $\pm S D$ of triplicate samples from at least two assays. Statistical comparison by Kruskal-Wallis test. 

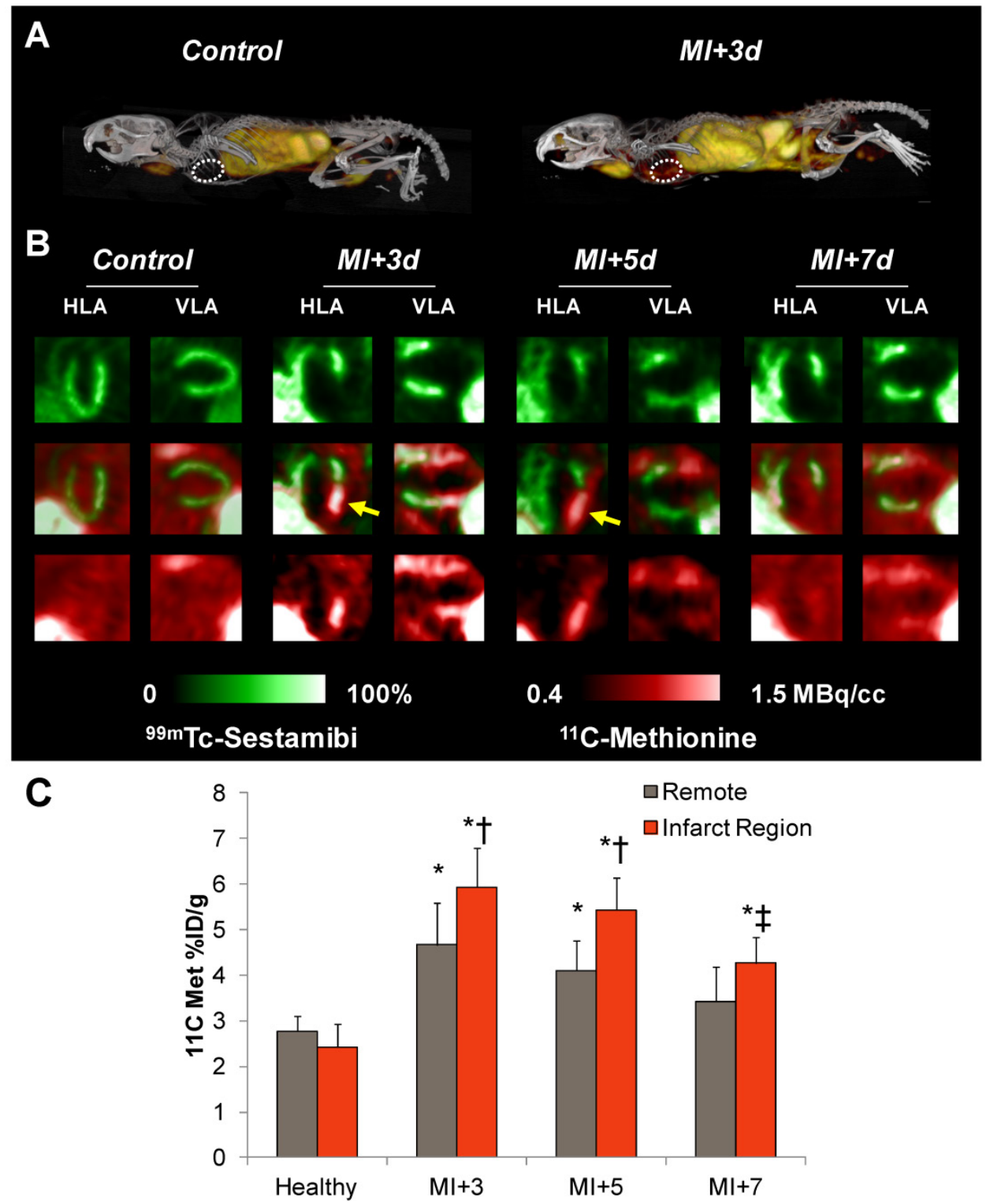

Figure 2. "IC-Methionine distribution in healthy mice and after myocardial infarction. A, Representative 3D maximum intensity projection $\mathrm{PET}-\mathrm{CT}$ images in a healthy mouse and at 3d after MI. B, Representative reoriented perfusion- I C-methionine SPECT-PET fusion cardiac images in a healthy mouse and serially after MI. Arrows indicate elevated methionine signal in the hypoperfused infarct region. C, Semiquantitative analysis of $11 \mathrm{C}$-methionine uptake (\% injected dose (ID)/g) in the apical anterolateral wall at $3 \mathrm{~d}, 5 \mathrm{~d}$, and $7 \mathrm{~d}$ post-MI. ${ }^{*} \mathrm{p}<0.05$ to healthy control, Kruskal Wallis test; $\ddagger \mathrm{P}<0.05$ to control and $\mathrm{Ml}+3 \mathrm{~d}$, repeated measure; $\dagger \mathrm{P}<0.05$ to matched remote myocardium, paired t-test.

\section{Ex Vivo Assessment Confirms "C-Methionine Association with Inflammatory Leukocytes}

The spatial distribution of ${ }^{11} \mathrm{C}$-methionine uptake was validated by ex vivo autoradiography and histopathology workup in adjacent sections. The anterolateral to inferoseptal wall activity ratio was enhanced two-to-fourfold in sections distal to the occlusion as compared to sections superior to the suture (Figure 3A and B). Histopathology in adjacent sections confirmed a high density of inflammatory leukocytes in the infarct territory and border zone, comprising CD68 positive macrophages and a smaller fraction of Ly6G positive granulocytes (Figure 3C).
CD11b-expressing cells isolated from the infarcted left ventricle displayed significantly higher methionine uptake compared to an equivalent fraction of CD11b-negative cells obtained from the same hearts $(0.36 \pm 0.09$ vs $0.15 \pm 0.07 \%$, $p<0.001)$ (Figure $3 \mathrm{D}$ ).

\section{Anti-Integrin Treatment Suppresses Inflammation and Lowers Myocardial 11C-Methionine Uptake.}

To assess the sensitivity of the ${ }^{11} \mathrm{C}$-methioine in vivo signal to therapeutic modulation of inflammation, a group of infarcted mice were pretreated ( $2 \mathrm{~h}$ prior to surgery) with a therapeutic antibody cocktail to inhibit integrin attachment to 
leukocytes and subsequent infiltration. Anti-integrin pretreatment significantly reduced the number of CD11b positive cells in the left ventricle at $3 \mathrm{~d}$ post-MI by $56 \%(0.5 \pm 0.3$ vs $1.2 \pm 0.3$ million, $p=0.015)$ (Figure 4C). A comparable decrease in accumulation of ${ }^{11} \mathrm{C}$-methionine was observed in the infarct territory, which was lower by $42 \%$ at $3 d(p=0.004)$ and $28 \%$ at $7 \mathrm{~d}(\mathrm{p}=0.03)$ compared to untreated infarct mice (Figure $4 \mathrm{~A}$ and $\mathrm{B}$ ). Infarct size at $7 \mathrm{~d}$, defined as the sestamibi perfusion defect, tended to be larger in anti-integrin treated mice compared to untreated $\mathrm{MI}$ mice $(60 \pm 4$ vs $44 \pm 9 \%, \mathrm{p}=0.02)$, but survival was comparable $(80 \% \quad(8 / 10) \quad$ untreated; $75 \% \quad(9 / 12)$ anti-integrin). Left ventricle weight was comparable between treated and untreated MI mice (Suppl Figure S3).

\section{I'C-Methionine PET After Acute Myocardial Infarction Can Be Translated to the Clinics.}

To determine whether the findings in mice can be translated to clinical application, a patient underwent myocardial perfusion SPECT and ${ }^{11} \mathrm{C}$-methionine PET at $3 \mathrm{~d}$ after first acute ST-elevation myocardial infarction followed by percutaneous coronary intervention for reperfusion of the occluded right coronary artery. A pattern similar to mice was observed, with elevated ${ }^{11} \mathrm{C}$-methionine signal in the hypoperfused infarct territory (most pronounced in the borderzone), along with mild diffuse uptake in remote myocardium (Figure 5). Extracardiac tracer distribution also resembled that of mice.
A

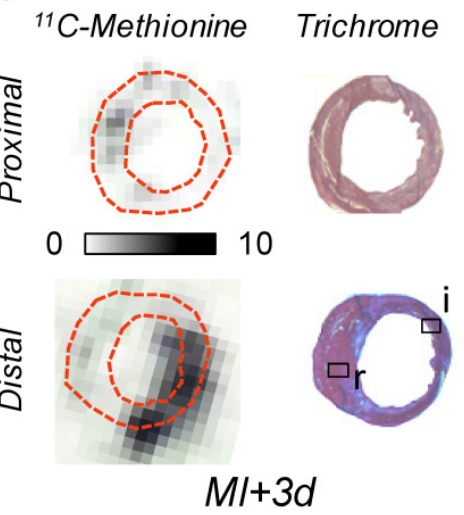

B

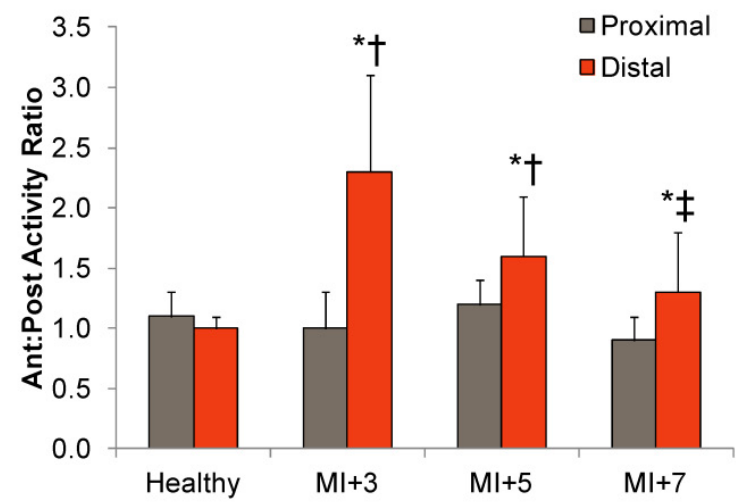

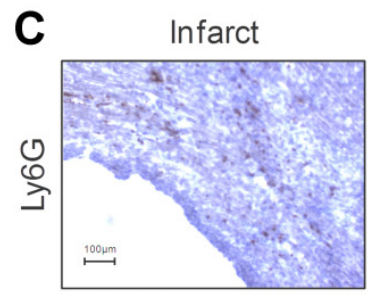

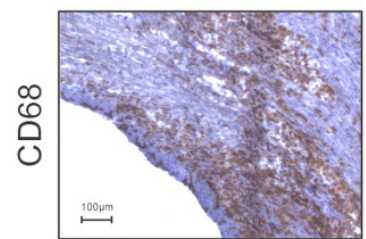

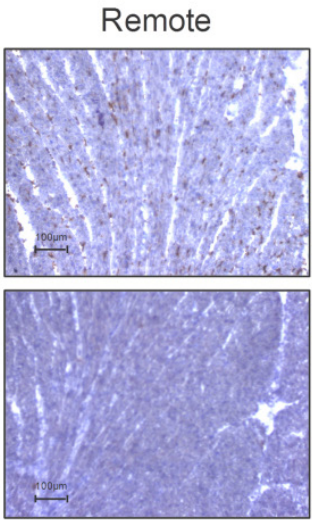

D

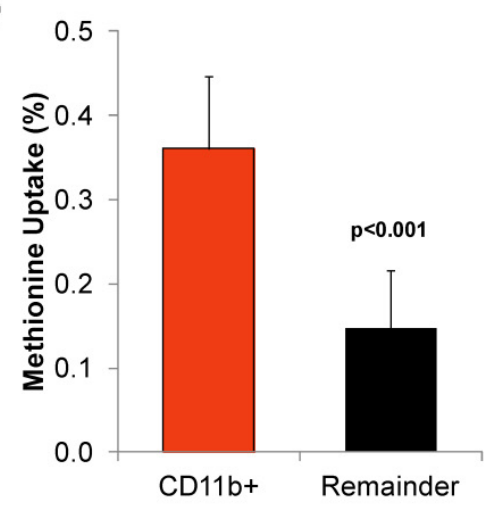

Figure 3. Correlative measurements of $11 \mathrm{C}$-methionine after myocardial infarction. A, Autoradiography with Masson trichome staining in adjacent sections confirms IIC-methionine association with activated leukocytes in the infarct region. B, Semi-quantitative autoradiography displays elevated anterolateral-to-posteroseptal wall activity below the coronary occlusion. * $\mathrm{p}<0.05$ to healthy control, $* * \mathrm{p}<0.05$ to control and $\mathrm{MI}+3 \mathrm{~d}$, Kruskal $\mathrm{Wallis}$ test; $\dagger \mathrm{p}<0.05$ to proximal sections, paired t-test. C, Immunostaining of CD68 macrophages or Ly6G polymorphonuclear cells (brown, hematoxylin counterstain) in infarct and remote myocardium at $3 \mathrm{~d}$ after myocardial infarction. $\mathbf{D}$, ${ }^{14} \mathrm{C}$-Methionine uptake by CD11b-expressing and non-expressing (remainder) cells isolated from the left ventricle by magnetic-associated cell separation, Kruskal Wallis test. 


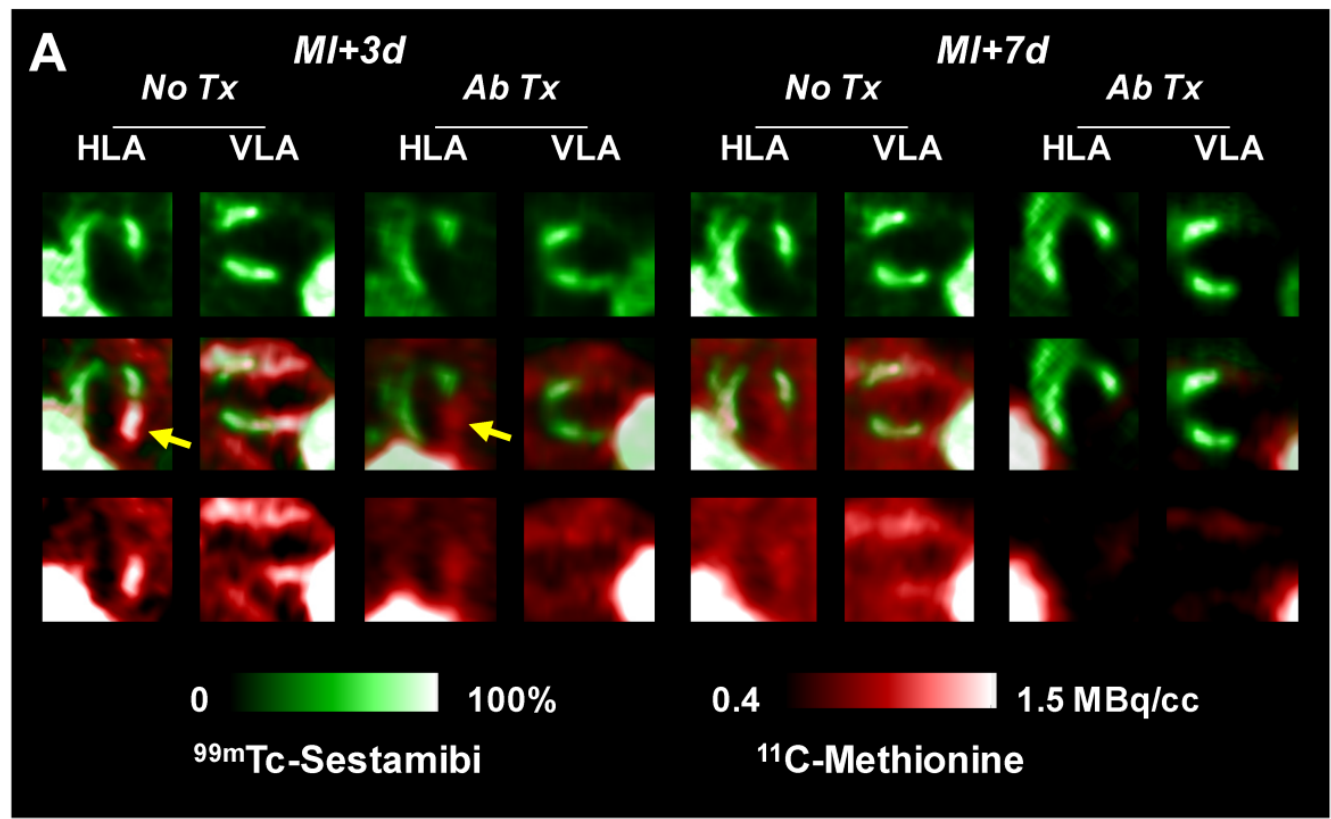

B

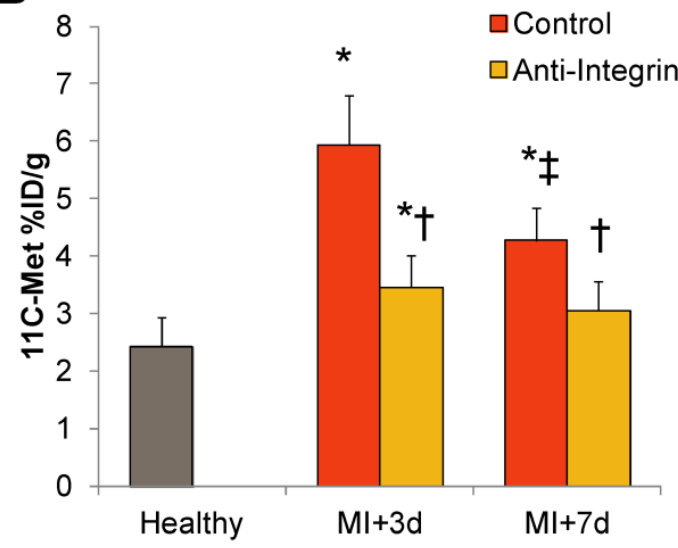

C

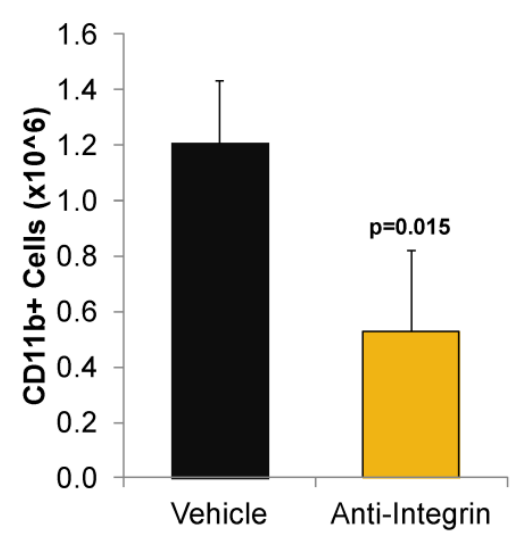

Figure 4. "C-Methionine uptake after myocardial infarction with suppressed inflammation by integrin antibody treatment. A, Representative reoriented PET-SPECT myocardial fusion images with and without antibody treatment at $3 \mathrm{~d}$ and $7 \mathrm{~d}$ post-MI. Arrows indicate attenuation of methionine signal in the hypoperfused infarct region. B, Semi-quantitative analysis shows " C -methionine accumulation (\% injected dose (ID)/g) is reduced by pretreatment with anti-integrin therapeutic antibody cocktail to prevent leukocyte attachment and infiltration. ${ }^{*} \mathrm{p}<0.05$ to healthy control, Kruskal Wallis test; $\ddagger \mathrm{p}<0.05$ to control and $\mathrm{Ml}+3 \mathrm{~d}$, repeated measure; $\dagger \mathrm{p}<0.05$ to matched remote myocardium, paired t-test. $\mathbf{C}$, Magnetic immunoseparation-derived CDI $1 \mathrm{~b}$ cell count in the left ventricle at $3 \mathrm{~d}$ after $\mathrm{MI}$ in vehicle- and anti-integrin treated mice, Kruskal Wallis test.

\section{Discussion}

This study establishes amino acid uptake as a specific target for molecular imaging of myocardial inflammation. The clinically established, radiolabelled amino acid methionine strongly accumulates in pro-inflammatory macrophages. This accumulation can be identified noninvasively and quantitatively in vivo within the infarct territory following $\mathrm{MI}$ in experimental animals and humans. Moreover, it is responsive to therapeutic modulation, as confirmed by attenuation of the imaging signal following inhibition of integrin-mediated leukocyte adhesion.

Our results are in line with a prior multi-tracer autoradiography study in rats, where transiently elevated methionine uptake was reported in the nonviable infarct region after $30 \mathrm{~min}$ of ischemia-reperfusion in rats [13]. In addition, the uptake of ${ }^{11} \mathrm{C}$-methionine in the infarct territory was assessed in acute MI patients, in combination with thallium-201 perfusion SPECT and 18F-FDG imaging for viability [12]. Importantly, these prior clinical images were obtained at inconsistent times after reperfusion, up to 2 weeks later, which affects not only the inflammatory state of the infarct, but also the homogeneity of the population studied. As such, the present study aimed to more clearly identify the cellular basis of ${ }^{11} \mathrm{C}$-methionine uptake, employing a combination of in vivo imaging, ex vivo molecular biology, and in vitro cellular uptake experiments to 
assess tracer distribution post-MI. The specificity of the imaging signal was further interrogated by applying anti-inflammatory treatment, which resulted in a comparable decrease in left ventricle macrophage content and ${ }^{11} \mathrm{C}$-methionine uptake.

As a marker of amino acid uptake for protein synthesis, ${ }^{11} \mathrm{C}$-methionine demarcates metabolically active cells in a number of states. The peak activity at $3 \mathrm{~d}$ post-MI is consistent with the presence of monocytes and macrophages. Indeed, increased protein synthesis is a characteristic of proliferating and differentiating cells, such as early infiltrating monocytes [20]. The recession of the signal by $7 d$ suggests a lower metabolic activity and protein synthesis in late-stage anti-inflammatory M2 macrophages, a pattern which was replicated in cell culture. In the present study, imaging was not conducted earlier than $3 \mathrm{~d}$ after MI, as this timeframe is not expected to be practical in clinical routine. As a result, the granulocyte peak, which occurs within $24 \mathrm{~h}$ after ischemic injury, is less likely to contribute to the in vivo methionine signal. Highest uptake in peripheral leukocytes is exhibited by cells involved in the early stages of inflammation, namely granulocytes, monocytes and macrophages. Such a

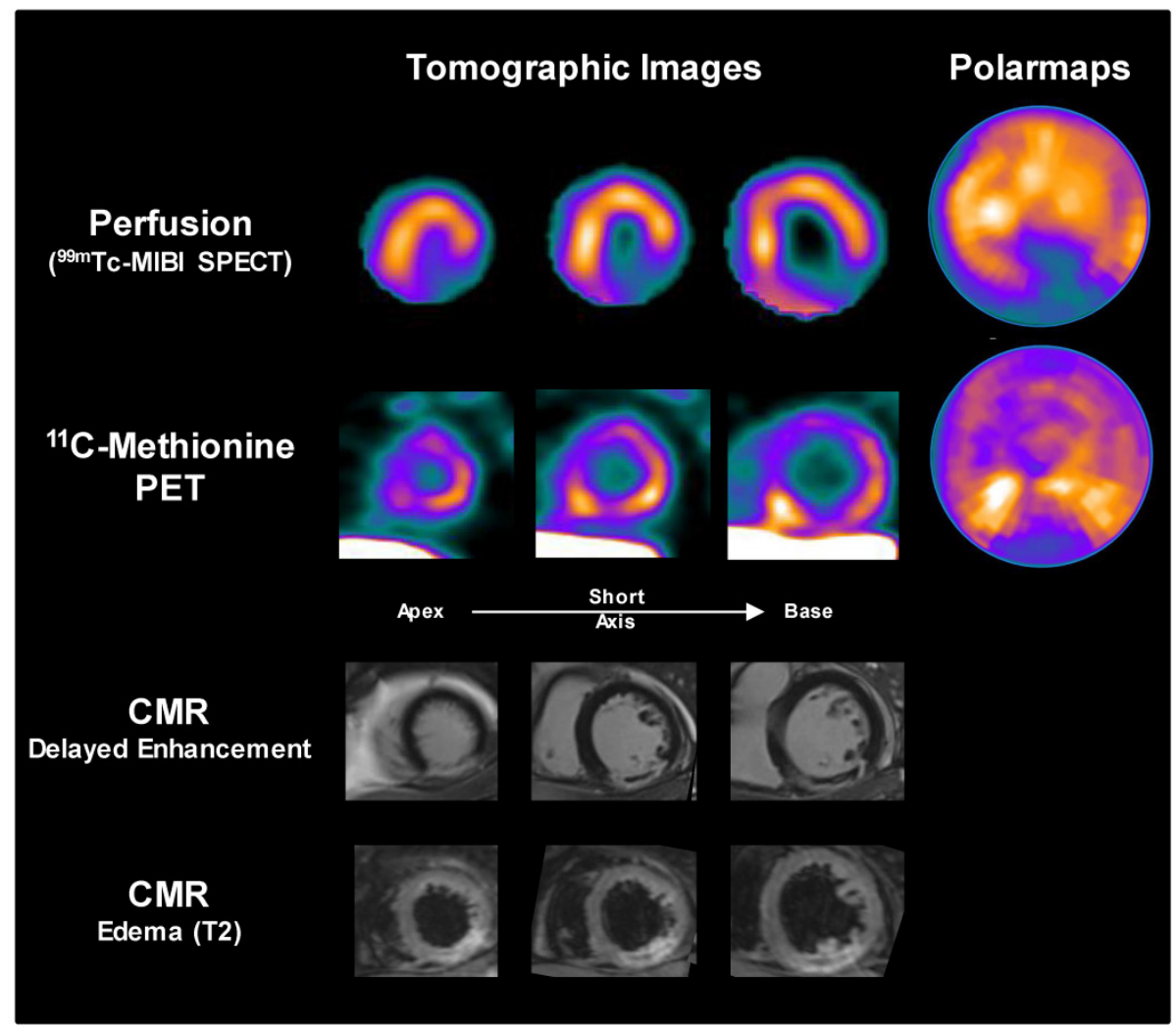

Figure 5. Sample images from a patient acquired 3d after acute myocardial infarction and reperfusion. Perfusion SPECT and IIC-methionine PET reoriented myocardial images and polar maps display diffuse myocardial uptake with elevated " C-methionine accumulation localized to the borderzone of the perfusion defect (yellow arrows). Cardiac magnetic resonance images (CMR) confirm delayed gadolinium enhancement in the infarct region, with central no-reflow area (red arrows), along with edema in the infarct region on T2 images. phenomenon has been described in vitro by comparing polarized macrophages, wherein higher uptake of the glucose analogue, ${ }^{18} \mathrm{~F}$-fluorodeoxyglucose (FDG) was observed in M1 macrophages over M2 macrophages [15], reflecting higher glucose metabolism in the pro-inflammatory cells. While isolation of primary macrophages from peripheral blood may provide a more natural generation of human macrophages than the THP-1 leukemic monocyte cell line, the differences observed in polarized macrophage uptake patterns are consistent with and directly comparable to the uptake of FDG in identically treated cells (data not shown) [15]. Indeed, these findings suggest that, among macrophage subpopulations, the inflammatory signal of both tracers may have a similar source. M1 and M2 polarization of macrophages represents a severe model of pro- and anti-inflammatory subsets. Though the tissue microenvironment post-MI likely contains a heterogeneous amalgamation of macrophage subtypes, the in vitro uptake assays suggest a preferential accumulation in activated inflammatory cells. This concept is further supported by the comparable uptake measured in CD11b-positive cells isolated from the left ventricle at $3 \mathrm{~d}$ post-MI. It is interesting to note that relatively high amino acid metabolism is observed in other immune cells, including neutrophils, monocytes, and CD2-positive lymphocytes isolated from peripheral blood. A wider range of leukocytes participating in the inflammatory process after myocardial infarction is consistent with systemic activation of humoral and innate immunity following MI $[5$, 21]. Nevertheless, $\mathrm{T}$ lymphocyte and NK cell accumulation in the infarct territory tends to occur later, with a peak at $7 \mathrm{~d}$ after MI, and the number of infiltrating cells is significantly lower than the earlier migration of neutrophils and macrophages [22]. Based on the timeframe and uptake characterization, the in vivo ${ }^{11} \mathrm{C}$-methionine signal appears most representative of activated pro-inflammatory $\quad$ M1 macrophages. 
Uptake of ${ }^{11} \mathrm{C}$-methoinine is governed by transmembrane transport by the sodium-independent L-amino acid transporter. This uptake is influenced by intracellular metabolic activity and is proportional to cell proliferation in oncology [23]. The early acquisition timepoint (i.e. $30 \mathrm{~min}$ ) renders it unlikely that in vivo images reflect de novo protein synthesis, but rather a measurement of amino acid transport and metabolic activity. The selectivity of methionine is further supported by the preferential uptake in M1 over M2 cultured macrophages. Whereas the metabolic activity of the cells is comparable, M2 cells are more phagocytically active, and therefore susceptible to non-specific accumulation of tracer. For example, iron oxide, which accumulates predominantly by phagocytosis, is more selective for M2 macrophages [15]. Inflammatory ${ }^{11} \mathrm{C}$-methionine uptake (by activated leukocytes) is cited as a potential confounding factor in oncology studies [24].

Previous reports have utilized FDG to identify inflammatory leukocytes within the infarct territory $[6,7]$. However, the robust uptake by healthy cardiomyocytes presents a considerable challenge for image acquisition and analysis, and necessitates strategies to suppress endogenous myocyte tracer uptake such as ketamine/xylazine anesthesia or extended fasting in rodents $[8,25]$, or high fat diet preparations and heparin administration in humans $[5,26]$. Such preparations have variable success and often lack clear translation between preclinical evaluation and clinical application. The frequent persistence of remote myocardial FDG uptake post-MI is an additional concern [7], as it is difficult to ascertain whether such uptake reflects inflammatory cells in the remote myocardium [6], or increased metabolism in viable but compromised cardiomyocytes. Like FDG, ${ }^{11} \mathrm{C}$-methionine is clinically applicable and broadly used for imaging of brain tumors and other malignancies [27, 28]. Owing to its shorter half-life, it results in lower effective dose [29]. As such, it presents several advantages over FDG including simplified imaging protocols, shorter acquisition times, free translation of methods between preclinical and clinical settings, and clearer delineation of the inflammation signal against normal myocardium.

The degree and severity of inflammation in the early stages after MI has been associated with infarct size, ventricular remodeling, and mortality. Patients with highest white blood cell count or increased circulating inflammatory cytokines tend to experience worse cardiac outcome [30, 31]. Unbalanced inflammation after myocardial infarction is thought to adversely impact the endogenous healing process. The long term impact on cardiac risk and the continued development of novel therapies targeting inflammation underscores the value of a noninvasive imaging approach to measure and monitor the recruitment and activation of inflammatory leukocytes early after MI. Moreover, a reliable imaging assay may be of value to the development of novel therapies to support the endogenous healing process [3].

Recent studies have identified the importance of balanced and controlled inflammation in limiting infarct size and adverse remodeling [32, 33]. The therapeutic antibody cocktail applied in the present study targets a selection of integrins expressed by patrolling leukocytes: LFA-1 and Mac-1 are implicated in leukocyte rolling and leukocyte migration; VLA- 4 regulates monocyte arrest, allowing for extravasation to the tissue [34]. The combined integrin antibodies effectively block leukocyte infiltration of the ischemic region [2], reflected by the attenuation of ${ }^{11} \mathrm{C}$-methionine accumulation. Cellular analysis of left ventricle digests by immunoseparation confirmed a marked reduction in CD11b-expressing leukocytes in the left ventricle at $3 \mathrm{~d}$ post-MI, which may contribute to the larger perfusion defect observed in treated animals. While complete inhibition of leukocyte migration to the infarct territory may result in impaired healing and higher incidence of left ventricular rupture [33], correctly timed therapy to block leukocyte subpopulations during the inflammatory cascade may facilitate the balance in inflammation conducive to optimal healing $[32,35]$. A precise molecular imaging assay may guide the appropriate timing of such treatments.

A more specific imaging assay for inflammatory cells may be of additional value in other cardiovascular and systemic diseases including atherosclerosis, myocarditis, or sarcoidosis, wherein competing uptake of FDG by native cardiomyocytes may complicate or obscure the inflammatory signal. In atherosclerosis, coronary arteries have been imaged using FDG [36], but the requisite suppression techniques of high-fat, low-carbohydrate feeding and heparin administration are suboptimal for routine practice. Similarly, FDG images in myocarditis or sarcoidosis may be equivocal due to inconsistent suppression of cardiomyocyte glucose uptake [37, 38], Alternatively, we and others have recently reported on the suitability of a tracer targeted to chemokine receptor (CXCL)-type 4 (CXCR4), ${ }^{68} \mathrm{Ga}$-pentixafor after MI [19, 39]. The potential benefit of ${ }^{11} \mathrm{C}$-methionine lies in its existing clinical deployment in oncology and the shorter positron range [40], which may improve image quality (especially for preclinical imaging in mice). Importantly, the spatial and temporal distribution of ${ }^{11} \mathrm{C}$-methionine post-MI 
emulates that of ${ }^{68} \mathrm{Ga}$-pentixafor, suggesting that similar target cells comprise the image.

Due to the mixed cell populations studied in vitro and the quantitative limitations of manual cell counting, the precise cellular basis of the methionine signal cannot be defined. Nevertheless, the uptake results from magnetic-associated immunoseparation support the notion that inflammatory macrophages are major contributors to the in vivo PET signal, particularly considering the congruent increase in CD11b-positive cells and ${ }^{11} \mathrm{C}$-methionine $\% \mathrm{ID} / \mathrm{g}$ in the infarct territory at $3 \mathrm{~d}$ after coronary ligation. Moreover, we have previously reported a proportional increase in CD45-positive leukocytes at the same timepoint (i.e. $3 \mathrm{~d}$ post-MI) by flow cytometry [7], supporting the cell count obtained by immunoseparation as an accurate representation of the cell population in the infarct territory.

Some limitations of the current approach for imaging inflammation should be acknowledged. Firstly, high activity in thymus and liver may interfere with myocardial assessment. In clinical cases, as opposed to preclinical animals, a greater anatomic separation between organs may improve delineation of the infarct regional activity. Additionally, novel algorithms for correction of respiratory and cardiac motion may be implemented in order to further increase separation and reduce motion-induced inaccuracy. Secondly, carbon-11 labeling requires an on-site cyclotron due to the short 20min half-life. Nevertheless, the current use of ${ }^{11} \mathrm{C}$-methionine in oncology, established radiosynthesis procedures, and documented safety profile are appealing for translation to clinical application. Many of the oncology applications of ${ }^{11} \mathrm{C}$-methionine can also be interrogated using an alternative labeled amino acid, ${ }^{18}$ F-fluoro-ethyl-tyrosine (FET) [41], which may be a suitable alternative for inflammation imaging, though dedicated studies to address this comparison have not yet been performed. Lastly, perfusion and ${ }^{11} \mathrm{C}$-methionine images were obtained sequentially using different cameras, resulting in lower confidence for image fusion as compared to using a single camera. The possibility of operator bias during analysis is mitigated by the inclusion of low-dose CT in the PET and SPECT protocols, enabling initial co-registration with the matched $\mathrm{CT}$ images and subsequent adjustment of the PET-SPECT fusion. The diffuse activity present in the remote myocardium post-infarct as well as the hepatic activity present for both tracers provide additional landmarks for accurate image fusion. Strategies including fiducial markers [6, 42] may be engaged for added confidence.

In conclusion, PET imaging with ${ }^{11} \mathrm{C}$-methionine provides a selective indication of localized tissue inflammation in the acute stages after myocardial infarction, declining over $7 \mathrm{~d}$ in parallel with activated inflammatory cells. The absence of cardiomyocyte uptake renders ${ }^{11} \mathrm{C}$-methionine particularly attractive compared to other established inflammation markers such as FDG. This preclinical work in combination with preliminary clinical experience provides the basis for future application in a clinical setting, where ${ }^{11} \mathrm{C}$-methionine molecular imaging may be used to assess efficacy and direct therapy targeted to modulating acute inflammation after myocardial infarction.

\section{Supplementary Material}

Supplementary figures.

http://www.thno.org/v06p1768s1.pdf

\section{Abbreviations}

$\mathrm{CT}$, computed tomography

CZT, cadmium-zinc-telluride

EDTA, ethylenediaminetetraacetic acid

FCS, fetal calf serum

FDG, ${ }^{18}$ F-fluoro-deoxyglucose

ID, injected dose

IFN $\gamma$, interferon- $\gamma$

IL4, interleukin-4

IL10, interleukin-10

LFA-1, lymphocyte function-associated antigen-1

(CD11a)

Mac-1, macrophage-1 antigen (CD11b)

MACS, magnetic associated cell sorting

M-CSF, macrophage colony-stimulating factor

$\mathrm{MI}$, myocardial infarction;

PBS, phosphate buffered saline

PET, positron emission tomography

SPECT, single photon emission computed

tomography

VLA-4, very late antigen-4 (CD49d)

\section{Acknowledgments}

The authors thank the Preclinical Molecular Imaging and Radiochemistry Laboratories (Nuclear Medicine) and the Molecular and Translational Cardiology Laboratory (Department of Cardiology and Angiology) for their assistance. This study was supported by the German Research Foundation (Excellence Cluster REBIRTH-2) and by EU FP7 grant PIRG08-GA_2010-276889 (FMB). JTT was supported by a fellowship from the Canadian Institutes of Health Research. The authors have declared that no competing interest exists.

\section{Competing Interests}

The authors have declared that no competing interest exists. 


\section{References}

1. White DA, Su Y, Kanellakis P, Kiriazis H, Morand EF, Bucala R, et al Differential roles of cardiac and leukocyte derived macrophage migration inhibitory factor in inflammatory responses and cardiac remodelling post myocardial infarction. J Mol Cell Cardiol. 2014; 69: 32-42.

2. Kempf T, Zarbock A, Widera C, Butz S, Stadtmann A, Rossaint J, et al. GDF-15 is an inhibitor of leukocyte integrin activation required for survival after myocardial infarction in mice. Nat Med. 2011; 17: 581-8.

3. Bengel FM, George RT, Schuleri KH, Lardo AC, Wollert KC. Image-guided therapies for myocardial repair: concepts and practical implementation. Eur Heart J Cardiovasc Imaging. 2013; 14: 741-51.

4. Nahrendorf M, Frantz S, Swirski FK, Mulder WJ, Randolph G, Ertl G, et al. Imaging systemic inflammatory networks in ischemic heart disease. J Am Coll Cardiol. 2015; 65: 1583-91.

5. Wollenweber T, Roentgen P, Schafer A, Schatka I, Zwadlo C, Brunkhorst T, et al. Characterizing the inflammatory tissue response to acute myocardial infarction by clinical multimodality noninvasive imaging. Circ Cardiovasc Imaging. 2014; 7: 811-8.

6. Lee WW, Marinelli B, van der Laan AM, Sena BF, Gorbatov R, Leuschner F, et al. PET/MRI of inflammation in myocardial infarction. J Am Coll Cardiol. 2012; 59: 153-63.

7. Thackeray JT, Bankstahl JP, Wang Y, Korf-Klingebiel M, Walte A, Wittneben A, et al. Targeting post-infarct inflammation by PET imaging: comparison of (68)Ga-citrate and (68)Ga-DOTATATE with (18)F-FDG in a mouse model. Eur J Nucl Med Mol Imaging. 2015; 42: 317-27.

8. Thackeray JT, Bankstahl JP, Wang Y, Wollert KC, Bengel FM. Clinically relevant strategies for lowering cardiomyocyte glucose uptake for 18F-FDG imaging of myocardial inflammation in mice. Eur J Nucl Med Mol Imaging. 2015; 42: 771-80.

9. Wykrzykowska J, Lehman S, Williams G, Parker JA, Palmer MR, Varkey S, et al. Imaging of inflamed and vulnerable plaque in coronary arteries with 18F-FDG PET/CT in patients with suppression of myocardial uptake using a low-carbohydrate, high-fat preparation. J Nucl Med. 2009; 50: 563-8.

10. Deng SM, Zhang B, Wu YW, Zhang W, Chen YY. Detection of glioma recurrence by (1)(1)C-methionine positron emission tomography and dynamic susceptibility contrast-enhanced magnetic resonance imaging: a meta-analysis. Nucl Med Commun. 2013; 34: 758-66.

11. Harris SM, Davis JC, Snyder SE, Butch ER, Vavere AL, Kocak M, et al. Evaluation of the biodistribution of 11C-methionine in children and young adults. J Nucl Med. 2013; 54: 1902-8.

12. Morooka M, Kubota K, Kadowaki H, Ito K, Okazaki O, Kashida M, et al. 11C-methionine PET of acute myocardial infarction. J Nucl Med. 2009; 50: 1283-7.

13. Taki J, Wakabayashi H, Inaki A, Imanaka-Yoshida K, Hiroe M, Ogawa K, et al. 14C-Methionine uptake as a potential marker of inflammatory processes after myocardial ischemia and reperfusion. J Nucl Med. 2013; 54: 431-6.

14. Langstrom B, Antoni G, Gullberg P, Halldin C, Malmborg P, Nagren K, et al. Synthesis of L- and D-[methyl-11C]methionine. J Nucl Med. 1987; 28: 1037-40.

15. Satomi T, Ogawa M, Mori I, Ishino S, Kubo K, Magata Y, et al. Comparison of contrast agents for atherosclerosis imaging using cultured macrophages: FDG versus ultrasmall superparamagnetic iron oxide. J Nucl Med. 2013; 54: 999-1004.

16. Korf-Klingebiel M, Reboll MR, Klede S, Brod T, Pich A, Polten F, et al. Myeloid-derived growth factor (C19orf10) mediates cardiac repair following myocardial infarction. Nat Med. 2015; 21: 140-9.

17. Kuang Y, Wang F, Corn DJ, Tian H, Lee Z. In vitro characterization of uptake mechanism of L-[methyl-(3)H]-methionine in hepatocellular carcinoma. Mol Imaging Biol. 2014; 16: 459-68.

18. Korf-Klingebiel M, Kempf T, Schluter KD, Willenbockel C, Brod T, Heineke J, et al. Conditional transgenic expression of fibroblast growth factor 9 in the adult mouse heart reduces heart failure mortality after myocardial infarction. Circulation. 2011; 123: 504-14

19. Thackeray JT, Derlin T, Haghikia A, Napp LC, Wang Y, Ross TL, et al. Molecular Imaging of the Chemokine Receptor CXCR4 After Acute Myocardial Infarction. JACC Cardiovasc Imaging. 2015; 8: 1417-26.

20. Swirski FK, Nahrendorf M. Leukocyte behavior in atherosclerosis, myocardial infarction, and heart failure. Science. 2013; 339: 161-6.

21. Weirather J, Hofmann UD, Beyersdorf N, Ramos GC, Vogel B, Frey A, et al. Foxp3+ CD4+ T cells improve healing after myocardial infarction by modulating monocyte/macrophage differentiation. Circ Res. 2014; 115: 55-67.

22. Hofmann U, Beyersdorf N, Weirather J, Podolskaya A, Bauersachs J, Ertl G, et al. Activation of CD4+ T lymphocytes improves wound healing and survival after experimental myocardial infarction in mice. Circulation. 2012; 125: 1652-63.

23. Glaudemans AW, Enting RH, Heesters MA, Dierckx RA, van Rheenen RW, Walenkamp AM, et al. Value of 11C-methionine PET in imaging brain tumours and metastases. Eur J Nucl Med Mol Imaging. 2013; 40: 615-35.

24. Kubota K. From tumor biology to clinical Pet: a review of positron emission tomography (PET) in oncology. Ann Nucl Med. 2001; 15: 471-86.

25. Fueger BJ, Czernin J, Hildebrandt I, Tran C, Halpern BS, Stout D, et al. Impact of animal handling on the results of 18F-FDG PET studies in mice. J Nucl Med. 2006; 47: 999-1006.

26. Kim EJ, Kim S, Kang DO, Seo HS. Metabolic activity of the spleen and bone marrow in patients with acute myocardial infarction evaluated by 18f-fluorodeoxyglucose positron emission tomograpic imaging. Circ Cardiovasc Imaging. 2014; 7: 454-60.

27. Yoo MY, Paeng JC, Cheon GJ, Lee DS, Chung JK, Kim EE, et al. Prognostic Value of Metabolic Tumor Volume on (11)C-Methionine PET in Predicting Progression-Free Survival in High-Grade Glioma. Nucl Med Mol Imaging. 2015; 49: 291-7.

28. Cicuendez M, Lorenzo-Bosquet C, Cuberas-Borros G, Martinez-Ricarte F, Cordero E, Martinez-Saez E, et al. Role of [(11)C] methionine positron emission tomography in the diagnosis and prediction of survival in brain tumours. Clin Neurol Neurosurg. 2015; 139: 328-33.

29. Deloar HM, Fujiwara T, Nakamura T, Itoh M, Imai D, Miyake $M$, et al. Estimation of internal absorbed dose of L-[methyl-11C]methionine using whole-body positron emission tomography. Eur J Nucl Med. 1998; 25: 629-33.

30. Barron HV, Harr SD, Radford MJ, Wang Y, Krumbolz HM. The association between white blood cell count and acute myocardial infarction mortality in patients $>$ or $=65$ years of age: findings from the cooperative cardiovascular project. J Am Coll Cardiol. 2001; 38: 1654-61.

31. Ammirati E, Cannistraci CV, Cristell NA, Vecchio V, Palini AG, Tornvall $P$, et al. Identification and predictive value of interleukin-6+ interleukin-10+ and interleukin-6- interleukin-10+ cytokine patterns in ST-elevation acute myocardial infarction. Circ Res. 2012; 111: 1336-48.

32. Nahrendorf M, Pittet MJ, Swirski FK. Monocytes: protagonists of infarct inflammation and repair after myocardial infarction. Circulation. 2010; 121: 2437-45

33. Horckmans M, Ring L, Duchene J, Santovito D, Schloss MJ, Drechsler M, et al. Neutrophils orchestrate post-myocardial infarction healing by polarizing macrophages towards a reparative phenotype. Eur Heart J. 2016.

34. Zarbock A, Kempf T, Wollert KC, Vestweber D. Leukocyte integrin activation and deactivation: novel mechanisms of balancing inflammation. J Mol Med (Berl). 2012; 90: 353-9.

35. Kempf T, Zarbock A, Vestweber D, Wollert KC. Anti-inflammatory mechanisms and therapeutic opportunities in myocardial infarct healing. $\mathrm{J}$ Mol Med (Berl). 2012; 90: 361-9.

36. Rogers IS, Nasir K, Figueroa AL, Cury RC, Hoffmann U, Vermylen DA, et al. Feasibility of FDG imaging of the coronary arteries: comparison between acute coronary syndrome and stable angina. JACC Cardiovasc Imaging. 2010; 3: 388-97.

37. Piriou N, Sassier J, Pallardy A, Serfaty JM, Trochu JN. Utility of cardiac FDG-PET imaging coupled to magnetic resonance for the management of an acute myocarditis with non-informative endomyocardial biopsy. Eur Heart J Cardiovasc Imaging. 2015; 16: 574.

38. Tang R, Wang JT, Wang L, Le K, Huang Y, Hickey AJ, et al. Impact of Patient Preparation on the Diagnostic Performance of 18F-FDG PET in Cardiac Sarcoidosis: A Systematic Review and Meta-analysis. Clin Nucl Med. 2015.

39. Lapa C, Reiter T, Werner RA, Ertl G, Wester HJ, Buck AK, et al. [(68)Ga]Pentixafor-PET/CT for Imaging of Chemokine Receptor 4 Expression After Myocardial Infarction. JACC Cardiovasc Imaging. 2015; 8: 1466-8.

40. Sanchez-Crespo A, Andreo P, Larsson SA. Positron flight in human tissues and its influence on PET image spatial resolution. Eur J Nucl Med Mol Imaging. 2004; 31: 44-51.

41. Weber WA, Wester HJ, Grosu AL, Herz M, Dzewas B, Feldmann HJ, et al. $\mathrm{O}-(2-[18 \mathrm{~F}]$ fluoroethyl)-L-tyrosine and L-[methyl-11C]methionine uptake in brain tumours: initial results of a comparative study. Eur J Nucl Med. 2000; 27: $542-9$.

42. Tong X, Garofalakis A, Dubois A, Boisgard R, Duconge F, Trebossen R, et al. Co-registration of glucose metabolism with positron emission tomography and vascularity with fluorescent diffuse optical tomography in mouse tumors. EJNMMI Res. 2012; 2: 19. 